\title{
... durch die Schwimmbrille eines TV-Stars gesehen ...
}

\section{Piero Lercher im amüsanten Gespräch mit TV-Star Barbara Karlich}

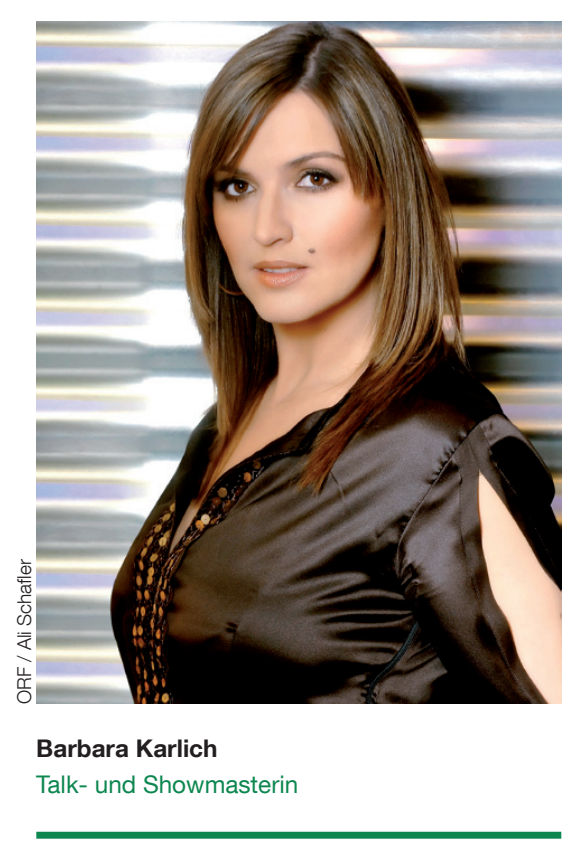

Welchen Stellenwert hat für Sie das Schwimmen?

BARBARA KARLICH: Einen fast so hohen wie essen und schlafen. Für mich ist schwimmen die einzige Sportart mit Wellnesseigenschaften.

Wie stehen Sie zum Thema Babyschwimmen?

B.K.: Bei Weltmeisterschaften und den Olympischen Spielen bin ich schwer dagegen. Nein, im Ernst - mein Mann und ich sind große Fans von Babyschwimmkursen, wir haben selber mit unserer Tochter Gloria an einigen teilgenommen.

Haben Sie eine spezielle Schwimmübung oder ein spezielles Schwimmritual, die/das Sie unseren Lesern empfehlen können?

B.K.: Ich lasse mich am liebsten von meinem Mann durchs Wasser ziehen, und habe davon noch nie einen Muskelkater bekommen.

\section{Wo schwimmen Sie am liebsten?}

B.K.: Definitiv im Meer. Der starke Auftrieb ermöglicht einem mit geringem Kraftaufwand Badespaß zu erleben.

Was verstehen Sie unter Schwimmkultur?

B.K.: William Shakespeare im Bikini.

Welche/r Schwimmer/in beeindruckt/e Sie am meisten und warum?

B.K.: Johnny Weissmüller war schon als Kind mein Idol. Und auch Bud Spencer, der mich figürlich an mich selbst erinnert. Beide haben durch den Schwimmsport Filmkarriere gemacht.

Wie überzeugen Sie einen SchwimmMuffel vom Gesundheitswert des Schwimmens?

B.K.: Wenn's sein muss mit Gewalt.

\section{Zur Person}

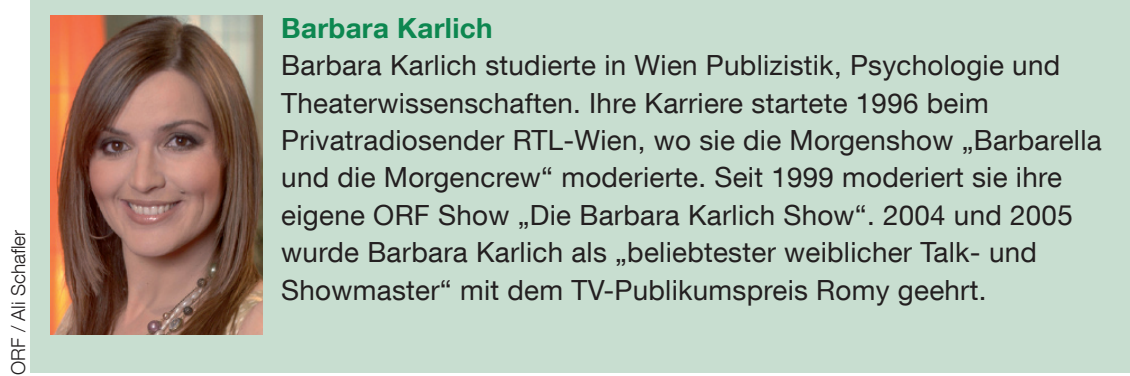

